\title{
Anxiety, worry, and job satisfaction: effects of COVID-19 care on critical care anesthesiologists
}

\author{
Shahla Siddiqui, MBBS, MSc (Medical Ethics), FCCM • Avery Tung, MD, \\ FCCM - Lauren Kelly, MPH (Statistics) - Michael Nurok, MBChB, \\ PhD, FCCM • Ashish K. Khanna, MD, FCCP, FCCM • Talia Ben-Jacob, MD, \\ MSc $\cdot$ Ricardo Verdiner, MD $\cdot$ Roshni Sreedharan, MD $\cdot$ Lena Novack, (Statistics) \\ Mark Nunnally, MD, FCCM · Jarva Chow, MD, MS, MPH · George W. Williams, MD, \\ FCCP, FCCM • Robert N. Sladen, MBChB, MRCP(UK), FRCPC, FCCM
}

Received: 20 October 2021/Revised: 15 December 2021/Accepted: 17 December 2021/Published online: 13 January 2022 (C) Canadian Anesthesiologists' Society 2022

Keywords Covid · burnout · anxiety $\cdot$ job satisfaction . gender disparity $\cdot$ critical care

\section{To the Editor,}

There is increasing evidence that the COVID-19 pandemic has had a significant psychological impact on intensivists. A survey conducted by the European Society of Intensive Care Medicine in early 2020 revealed a $30-50 \%$ incidence of depression, anxiety, and severe burnout. ${ }^{1}$ In late 2020, we conducted an observational cross-sectional survey to evaluate the impact of the pandemic on anxiety and job satisfaction among critical care anesthesiologists in the USA. We utilized an anonymous online survey that included questions on

An American Society of Anesthesiologists Committee on Critical Care Medicine work project.

S. Siddiqui, MBBS, MSc (Medical Ethics), FCCM ( () )

L. Kelly, MPH (Statistics)

Department of Anesthesia, Critical Care and Pain Medicine,

Beth Israel Deaconess Medical Center, Boston, MA, USA

e-mail: shahlasi@yahoo.com

A. Tung, MD, FCCM - J. Chow, MD, MS, MPH

Department of Anesthesia and Critical Care, University of

Chicago, Chicago, IL, USA

M. Nurok, MBChB, PhD, FCCM

Cardiac Surgery Intensive Care Unit, Cedars Sinai Medical

Center, Los Angeles, CA, USA

A. K. Khanna, MD, FCCP, FCCM

Department of Anesthesiology, Section on Critical Care

Medicine, Wake Forest University School of Medicine,

Winston-Salem, NC, USA demographic information, the Generalized Anxiety Disorder Questionnaire-IV ${ }^{2}$ and open-ended questions asking respondents how they managed fear, anxiety, loss of control, and stress during the pandemic. A second section allowed participants to provide comments and recommendations for situational improvement. The survey was pretested by the American Society of Anesthesiologists (ASA) Committee on Critical Care Medicine and emailed to 1,400 members of the ASA, the Society of Critical Care Anesthesiologists, and the Anesthesiology Section of the Society of Critical Care Medicine.

The evaluable response rate was $21 \%(300 / 1,400)$. The median [interquartile range] age of respondents was 44 [37-55] yr; 51\% (144/282) were < 45 yr, 31\% (92/299) were female, $65 \%(195 / 298)$ practiced in an academic setting, and 20\% (61/300) were foreign medical graduates. Criteria for generalized anxiety disorder were met by $42 \%$ of respondents (55\% of females vs $37 \%$ of males; Chi

T. Ben-Jacob, MD, MSc

Anesthesiology and Critical Care Medicine, Cooper University Hospital, Camden, NY, USA

R. Verdiner, MD

Anesthesiology and Critical Care Medicine, Mayo Clinic, Phoenix, AZ, USA

R. Sreedharan, MD

Anesthesiology and Critical Care Medicine, Cleveland Clinic, Cleveland, OH, USA

L. Novack, (Statistics)

Department of Anesthesia, Critical Care and Pain Medicine, Beth Israel Deaconess Medical Center, Boston, MA, USA

Soroka University Medical Center, Beer-Sheva, Israel 
Table Demographic factors and symptoms of anxiety (multivariate analysis)

\begin{tabular}{|c|c|c|c|c|}
\hline Symptom & $\begin{array}{l}\text { Practice setting } \\
\text { (private } v s \\
\quad \text { academic) } \\
\text { OR }(95 \% \mathrm{CI})\end{array}$ & $\begin{array}{l}\text { Gender } \\
(\text { female } v s \\
\quad \text { male })^{\mathrm{b}} \\
\text { OR }(95 \% \mathrm{CI})\end{array}$ & $\begin{array}{l}\text { Age } \\
(<45 \text { yr } v s \geq 45 \\
{\text { yr })^{\mathrm{c}}}^{\text {OR }(95 \% \mathrm{CI})}\end{array}$ & $\begin{array}{l}\text { Foreign Medical } \\
\text { Graduate status } \\
\text { (US vs foreign) }^{\mathrm{d}} \\
\text { OR }(95 \% \mathrm{CI})\end{array}$ \\
\hline Restlessness or feeling keyed up or on edge & $\begin{array}{l}0.99(0.56 \text { to } \\
1.75) \\
(N=262) \\
P=0.97\end{array}$ & $\begin{array}{l}1.79(1.03 \text { to } \\
3.13) \\
(N=262) \\
P=0.04\end{array}$ & $\begin{array}{l}1.70(0.98 \text { to } \\
2.95) \\
(N=262) \\
P=0.06\end{array}$ & $\begin{array}{l}1.15(0.59 \text { to } 2.22) \\
(N=263) \\
P=0.68\end{array}$ \\
\hline Irritability & $\begin{array}{l}1.05(0.60 \text { to } \\
1.83) \\
(N=261) \\
P=0.87\end{array}$ & $\begin{array}{l}1.37(0.78 \text { to } \\
2.39) \\
(N=261) \\
P=0.27\end{array}$ & $\begin{array}{l}1.95(1.12 \text { to } \\
3.37) \\
(N=261) \\
P=0.02\end{array}$ & $\begin{array}{l}0.76(0.40 \text { to } 1.44) \\
(N=274) \\
P=0.40\end{array}$ \\
\hline Difficulty falling/staying asleep or restless/unsatisfying sleep & $\begin{array}{l}1.61(0.91 \text { to } \\
2.84) \\
(N=260) \\
P=0.10\end{array}$ & $\begin{array}{l}1.79(1.02 \text { to } \\
\quad 3.16) \\
(N=260) \\
P=0.04\end{array}$ & $\begin{array}{l}1.49(0.85 \text { to } \\
2.62) \\
(N=260) \\
P=0.16\end{array}$ & $\begin{array}{l}1.34(0.69 \text { to } 2.61) \\
(N=273) \\
P=0.39\end{array}$ \\
\hline Being easily fatigued & $\begin{array}{l}1.21(0.69 \text { to } \\
2.1) \\
(N=261) \\
P=0.51\end{array}$ & $\begin{array}{l}2.50(1.42 \text { to } \\
\quad 4.40) \\
(N=261) \\
P=0.002\end{array}$ & $\begin{array}{l}1.27(0.74 \text { to } \\
2.18) \\
(N=261) \\
P=0.39\end{array}$ & $\begin{array}{l}1.25(0.67 \text { to } 2.34) \\
(N=274) \\
P=0.49\end{array}$ \\
\hline Difficulty concentrating or mind going blank & $\begin{array}{l}0.95(0.50 \text { to } \\
1.81) \\
(N=259) \\
P=0.87\end{array}$ & $\begin{array}{l}1.72(0.94 \text { to } \\
\quad 3.16) \\
(N=259) \\
P=0.08\end{array}$ & $\begin{array}{l}2.16(1.14 \text { to } \\
\quad 4.09) \\
(N=259) \\
P=0.02\end{array}$ & $\begin{array}{l}0.79(0.38 \text { to } 1.67) \\
(N=272) \\
P=0.54\end{array}$ \\
\hline Muscle tension & $\begin{array}{l}1.06(0.60 \text { to } \\
1.88) \\
(N=257) \\
P=0.84\end{array}$ & $\begin{array}{l}3.09(1.74 \text { to } \\
\quad 5.5) \\
(N=257) \\
P<0.001\end{array}$ & $\begin{array}{l}1.93(1.10 \text { to } \\
3.40) \\
(N=257) \\
P=0.02\end{array}$ & $\begin{array}{l}0.72(0.38 \text { to } 1.37) \\
(N=270) \\
P=0.32\end{array}$ \\
\hline $\begin{array}{l}\text { Worry and physical symptoms interfere with life, work, social } \\
\text { activities, family, etc. }\end{array}$ & $\begin{array}{l}1.24(0.68 \text { to } \\
2.26) \\
(N=262) \\
P=0.48\end{array}$ & $\begin{array}{l}2.75(1.55 \text { to } \\
\quad 4.87) \\
(N=262) \\
P<0.001\end{array}$ & $\begin{array}{l}1.73(0.95 \text { to } \\
3.12) \\
(N=262) \\
P=0.07\end{array}$ & $\begin{array}{l}0.72(0.37 \text { to } 1.41) \\
(N=275) \\
P=0.34\end{array}$ \\
\hline
\end{tabular}

a Adjusted to gender and age

b Adjusted to practice setting and age

c Adjusted to practice setting, gender, Foreign Medical Graduate Status

d Adjusted to age

$\mathrm{CI}=$ confidence interval; $\mathrm{OR}=$ odds ratio

M. Nunnally, MD, FCCM

Department of Anesthesiology, NYU Langone Health, NYU School of Medicine, New York, NY, USA

G. W. Williams, MD, FCCP, FCCM

Department of Anesthesiology, UTHealth McGovern Medical School at Houston, Houston, TX, USA

\section{R. N. Sladen, MBChB, MRCP(UK), FRCPC, FCCM}

Columbia University Irving Medical Center and Vagelos College of Physicians \& Surgeons of Columbia University, New York, NY, USA square test, $P=0.003)$. Overall, $32 \%$ reported moderate to severe symptoms of anxiety but these were significantly more common in females and younger respondents (Table). Seventy-three percent of female vs $58 \%$ of male respondents reported that working as an intensivist during the pandemic had increased their sense of burnout $(P<$ 0.001 ), and $75 \%$ of all respondents considered that institutional wellness resources were unhelpful. During the pandemic, $64 \%$ of respondents considered their contribution towards critical care in their institution to be increased, $30 \%$ unchanged, and $7 \%$ stated that their contribution declined. A sense of enhanced achievement 
and satisfaction with their professional life was reported by $44 \%$ of respondents; $28 \%$ reported no change and $28 \%$ reported a decline $(38 \%$ of females vs $24 \%$ of males, $P=$ 0.04). Responses to open-ended questions revealed concerns about shortages of personal protective equipment, inadequate staffing, and the safety of caregivers and their families, balanced by positive feelings of teamwork and support and a sense of sacrifice and care for others. Respondents considered that their expertise in airway management enhanced the perception of their value in pandemic care by other healthcare providers.

Broad applicability of our results is limited by the evaluable response rate of $21 \%$, although this is similar to that of recent comparable surveys. ${ }^{1,3,4}$ Further, the survey was conducted prior to the wide availability of caregiver vaccination. Nonetheless, the findings indicate that the COVID-19 pandemic is associated with a high incidence of generalized anxiety disorder and an increased sense of burnout among critical care anesthesiologists, particularly in females and younger physicians. This is balanced by enhanced job satisfaction and a sense of being respected and valued for contributions during the pandemic. The significant gender difference in anxiety, burnout, and job satisfaction may in part be a consequence of the increased burden that female intensivists bear through their responsibilities outside the workplace. Our findings suggest that, particularly during the COVID-19 pandemic, improved institutional intervention is warranted to support wellness among critical care anesthesiologists and to enhance workplace support for female intensivists.

Disclosures None.

Funding statement Support was provided solely from institutional and/or departmental sources.

Editorial responsibility This submission was handled by Dr. Stephan K.W. Schwarz, Editor-in-Chief, Canadian Journal of Anesthesia/Journal canadien d'anesthésie.

\section{References}

1. Azoulay E, De Waele J, Ferrer R, et al. Symptoms of burnout in intensive care unit specialists facing the COVID-19 outbreak. Ann Intensive Care 2020; DOI: https://doi.org/10.1186/s13613-02000722-3.

2. Newman $M G$, Zuellig AR, Kachin KE, et al. Preliminary reliability and validity of the generalized anxiety disorder questionnaire-IV: a revised self-report diagnostic measure of generalized anxiety disorder. Behav Ther 2002; 33: 215-33.

3. Afonso AM, Cadwell JB, Staffa SJ, Zurakowski D, Vinson AE. Burnout rate and risk factors among anesthesiologists in the United States. Anesthesiology 2021; 134: 683-96.

4. Siddiqui S, Bartels K, Schaefer MS, et al. Critical care medicine practice: a pilot survey of US anesthesia critical care medicinetrained physicians. Anesth Analg 2021; 132: 761-9.

Publisher's Note Springer Nature remains neutral with regard to jurisdictional claims in published maps and institutional affiliations. 